\title{
Ders Geçme Notlarının Veri Madenciliği Yöntemleriyle Tahmin Edilmesi
}

\author{
Emrah Aydemir ${ }^{*}$ \\ ${ }^{1}$ Kırşehir Ahi Evran Üniversitesi, Bilgisayar Mühendisliği Bölümü, Kırşehir, Türkiye (ORCID: 0000-0002-8380-7891)
}

(İlk Geliş Tarihi 28 Ocak 2019 ve Kabul Tarihi 1 Mart 2019)

(DOI: 10.31590/ejosat.518899)

ATIF/REFERENCE: Aydemir, E. (2019). Ders Geçme Notlarının Veri Madenciliği Yöntemleriyle Tahmin Edilmesi. Avrupa Bilim ve Teknoloji Dergisi, (15), 70-76.

$\ddot{O} z$

Teknolojinin gelişimi ile veritabanlarının boyutları doğru orantılı olarak ilerlemektedir. Bu kadar çok verinin tutulması sonucu çeşitli analizler ile bu veriler arasındaki gizli bağlantıların araştııılması kaçınılmaz olmuştur. Buradaki çalışmada öğrencilerin Yabancı Dil-II dersindeki geçme notları veri madenciliği yöntemleriyle tahmin edilmiştir. Araştırmada Türkiye'deki bir üniversitede Yabancı Dil-II dersini alan 3794 öğrenci verileri kullanılmıştır. Çalışmada 12'si girdi ve biri çıktı olmak üzere toplam 13 adet değişkenin yer aldığı Yapay Sinir Ağları, M5P, DecisionStump, M5Rules, DecisionTable, Bagging yöntemleri ile geliştirilen tahmin modelleri oluşturulmuş ve birbirleriyle karşılaştırılmıştır. Verilerin eğitim ve test olarak ayrıştırılmasında 10-katlı çapraz doğrulama yöntemi kullanılmıştır. Modellerde öğrencinin ders geçme notunu etkileyecek öğrenim tipi, fakülte, bölüm, program, program tipi, öğretim elemanı ve unvanı, öğrenci programa giriş türü, giriş puanı ve giriş sıralaması ile bir önceki dönemin not ortalaması dikkate alınmıştır. Modeller arasında Bagging yöntemi ile kurulan modelin en iyi sonuç olan 1.22 ortalama mutlak hata ve 0.80 korelasyon katsayısı ile tahminler ürettiği görülmüştür. Çalışma sonucunda öğrencilerin ders geçme notunu önceden öğrenip önlemler alacağı düşünülmektedir.

\section{Forecasting of The Course Learning Notes by Data Mining Methods}

\begin{abstract}
With the development of technology, the dimensions of the databases are progressively proportional. It is inevitable to investigate the secret links between these analyzes with various analyzes. In this study, the passing grades of the students in Foreign Language-II course were estimated by data mining methods. In the study at a university in Turkey Foreign Language-II 3794 students taking the course data are used. In this study, the estimation models developed by Artificial Neural Networks, M5P, DecisionStump, M5Rules, DecisionTable and Bagging methods were formed and compared with each other. 10-fold cross-validation method was used for training and testing. In the models, the type of the course, faculty, department, program, program type, teaching staff and title, the type of entry to the program, entry point and entry rank and the average grade of the previous semester were taken into consideration. Among the models, it was seen that the model established with Bagging method produced the best results with 1.21 mean absolute error and 0.81 correlation coefficient. As a result of the study, it is thought that the students will learn the course grade and take precautions in advance.
\end{abstract}

Keywords: Data Mining, Academic Success, Forecasting.

\footnotetext{
* Sorumlu Yazar: Kırşehir Ahi Evran Üniversitesi, Bilgisayar Mühendisliği Bölümü, Kırşehir, Türkiye, ORCID: 0000-0002-8380-7891, emrah.aydemir@ahievran.edu.tr
} 


\section{Giriş}

Verilerin elektronik ortamda saklanmasının gelişmesi ve çeşitli analiz araçlarının ortaya çıkması ile veri ambarlarının işlenmesi sonucu veri madenciliği de günden güne gelişmektedir. Öğrencilere ait bu büyük boyutlu veri ambarlarındaki verilerin işlenmesi sonucu yeni bilgilerin elde edilmesi eğitimde veri madenciliği olarak görülebilir. Fakat eğitimde bu kadar çok veri tutulurken verinin daha etkin ve verimli olarak saklanılmasına odaklanılıp veriler üzerinde yapılabilecek analizler arka planda kalabilmektedir. Verilerin işlenmesi ve bilgi üretilmesi için veri madenciliği tanımlayıcı ve öngörüye yönelik modeller üretmektedir. Karar alma süreçlerinde öngörü yöntemine, başarılı kararların alınmasında yüksek fayda sağlaması nedeniyle ilgi artmakta ve yeni yöntemler ortaya çıkmaktadır (Yurtoğlu, 2005). Bilhassa öğrencilerin hangi alanda başarılı olabileceklerine, başarılarını etkileyen unsurların belirlenmesine, başarı seviyelerine, başarısızlığa neden olan unsurların belirlenmesine olanak sağlayabilir.

Geçmişten beri güncel bir şekilde araştırma konusu olan insan beyninin gösterdiği işlev ve ürettiği tepkileri anlayarak beynin çalışma prensibini çözme (Doğan, 2002) özellikle öğrenmenin ne düzeyde gerçekleştiği ve değiştiğini anlamaya yardımcı olacaktır. Böylece öğrenme sürecindeki davranış değişiklikleri ölçülecek ve öğrenmenin değerlendirilmesi imkânı doğacaktır (Karip, 2012). Öğrenmenin çeşitli ölçme yöntemleri sonucunda not veya puan gibi değerler ile gösterilmesi akademik başarı olarak yorumlanabilir (Turgut ve Baykul, 2013). Öğrenciler akademik başarıları seviyelerini önceden bilmeyi isteyecektir fakat bunun yanı sıra Yükseköğretim Kurumları da bu durumu önceden bilmeyi isteyecektir (Luan, 2002). Bu durum da ancak veri madenciliği yöntemleri ile mümkün olacaktır. Her ne kadar da teknik bilgi, veri madenciliği uzmanı ve bu alana ayrılan finansal kaynakların yetersiz olması nedeniyle eğitim alanında veri madenciliği sınırlı olarak kullanılıyorsa da (Beitel, 2005) bu alan eğitimi geliştirmek için önemini korumaktadır (Siemens ve Baker, 2012).

Literatürdeki eğitim alanında veri madenciliğinin kullanılmasına yönelik çalışmalar incelendiğinde birçok çalışmanın varlığına rastlanmıştır. Veri madenciliği yöntemleri, öğrenci davranışlarını veya başarılarını analiz ederek öğrenci performansını tahmin eden modeller geliştirmek için kullanılmıştır (Sembiring ve ark., 2011; Shovon ve Haque, 2012). Yine benzer şekilde üniversitelerin öğrenci işleri veritabanından elde edilen veriler veri madenciliği yöntemleri ile analiz edilmiş ve öğrenci başarısı irdelenmiştir (İnan, 2003; Erdoğan, 2004; Altınışık, 2006; Kılınç, 2015). Bir başka çalışmada da öğrencilere ait fakülte, not ortalaması, cinsiyeti, giriş tipi, medeni hali, lise not ortalaması, ÖSS puanı, tercih sırası ve yüzdelik dilimi bilgilerinden yararlanılarak öğrenci başarısını önceden tahmin etmek amaçlanmıştır. Buradaki çalışmada da öğrenim tipi, fakülte, bölüm, program, program tipi, öğretim elemanı ve unvanı, öğrenci programa giriş türü, giriş puanı ve giriş sıralaması ile bir önceki dönemin not ortalaması dikkate alınmış ve çeşitli veri madenciliği yöntemleri ile ders geçme başarısı tahmin edilmiştir.

\section{Veri Madenciliği ve Kullanılan Yöntemler}

Veri yığınları arasında gizli kalmış, bir kısım analizler sonucu geçerli ve işe yarar bilgi elde edilmesine veri madenciliği denir (Aydemir, 2018). Veri madenciliği büyük miktardaki veriler üzerinde işlem yapması nedeniyle veritabanları ile doğrudan ilişkilidir. Veri madenciliği belirli bir amaca yönelik oluşturulan, hızlı ve etkin bir şekilde erişim olanağı tanıyan veri ambarlarından yararlanır. Veri madenciliği kendi başına çözüm olmayıp problem çözümü için gerekli bilgileri sağlar ve karar verme sürecini destekler (Baykal, 2006). Veri madenciliğinde kullanılan yöntemleri aşağıdaki şekilde sınıflandırmak mümkündür:

\subsection{Kümeleme}

Sınıfları belli olmayan veriler içerisinde, birbirine belirli ölçülerde benzerlik taşıyan öğelerin bir araya getirilip kümelere ayrılması yöntemlerinden oluşur (Han ve Kamber, 2006). Kümeleme yönteminde küme sayısı verilerin niteliklerinden doğrudan etkilenir.

\subsection{Birliktelik}

Geçmiş veriler içerisindeki birlikte geçme olma davranışlarının tespit edilerek ortaya çıkarılması yöntemleridir. Bu durumun tespit edilmesinde verilerin birden fazla satırda yer alması gerekir. Veri kümelerinin üyeleri arasındaki ilişkileri ortaya çıarır ve özellikle pazarlama alanında sık kullanılır (Oğuzlar, 2004).

\subsection{Tahminler}

Tahminler, sonuçları bilinen veriler ile bir model geliştirip sonuçları bilinmeyen veri kümelerinin sonuç değerlerini tahmin etmenin amaçlandığı yöntemlerdir. Sonuç değerinin sayısal bir değer veya kategorik bir değer olmasına göre kullanılan yöntemler sayısal tahminler ve kategorik tahminler (sınıflandırma) olmak üzere ikiye ayrılabilir.

\section{Yöntem}

Çalışmada büyük veri kümeleri arasından anlamlı bilgilerin çıkarıldığı veri madenciliği yöntemleri kullanılmıştır. Veri madenciliği eldeki verilerden hareketle sonuçları bilinmeyen verilerin tahmin edilmesi için kullanılır (Akpınar, 2000). Buradaki çalışmada da Türkiye'deki bir üniversitede öğrenim görmekte olan lisans ve önlisans öğrencilerinin 2017-2018 eğitim-öğretim yılının güz ve bahar dönemlerine ait Yabancı Dil-II ders notları diğer detayları ile birlikte veri madenciliği yöntemleri ile analiz edilmiş ve dönem sonu geçme notu tahmin edilmiş̧ir. 3794 adet öğrenciye ait 13 adet nitelik aşağıdaki gibi belirlenmiştir.

1. Öğrenim Tipi 
2. Fakülte

3. Bölüm

4. Program

5. Program Tipi

6. Öğretim Elemanı

7. Öğretim Elemanı Unvanı

8. ÖSS Giriş Türü

9. ÖSS Giriş puanı

10. ÖSS Giriş Sıralaması

11. Bir Önceki Dönemin Not Ortalaması

12. Aktif Dönem Not Ortalaması

13. Ders Geçme Notu

Öğrencinin Yabancı Dil-I dersinin notu Yabancı Dil-II notunun da oluşmasında belirleyici bir unsurdur. Fakat Yabancı Dil-II dersinin notları ile Yabancı Dil-I dersinin notları büyük oranda benzerlik göstermesi nedeniyle oluşturulan modelin olumsuz etkileneceği düşünülmüş ve girdi değeri olarak dikkate alınmamıştır. Derse ait geçme notu sistemde harf olarak tutulmuş ve harfler aşağıdaki şekilde sayılara dönüştürülmüştür. Sıfır değeri verinin yokluğunu ifade ettiği için notlar bir değerinden başlatılmıştır.

Tablo 1. Harf Notları ve Sayısal Karşılıkları

\begin{tabular}{l|l}
\hline Harf Notu & Sayısal Karşılı̆̆ $\mathbf{~}$ \\
\hline AA & 10 \\
\hline BA & 9 \\
\hline BB & 8 \\
\hline BC & 7 \\
\hline CB & 6 \\
\hline CC & 5 \\
\hline DC & 4 \\
\hline DD & 3 \\
\hline FD & 2 \\
\hline FF & 1 \\
\hline
\end{tabular}

Çalışmada ders geçme notlarının sayısal karşılıkları tahmin edilmiştir. Bu nedenle kullanılan veri madenciliği yöntemleri de sayısal veriler üzerinde işlem yapan yöntemlerdir. Kurulan modelin başarısı için ortalama mutlak hata (MAE), korelasyon katsayısı ( $r$ ) ve hata karelerinin ortalamasının karekökü (RMSE) dikkate alınmıştır. Ortalama mutlak hata için aşağıdaki formül kullanılır.

$$
\text { Ortalama mutlak hata }=\frac{\sum_{i=1}^{n}\left|\hat{\theta}_{i}-\theta_{i}\right|}{n}
$$

$n=$ örneklem sayısı

$\theta_{i}=i$ sira numarall gerçek talep

$\hat{\theta}_{i}=i$ sira numaralının tahmin edilen talebi

$i=$ örneklem sirası

Ortalama mutlak hata değeri tahmin edilen veri ile gerçek veri arasındaki farkın mutlak değerlerinin ortalamasıdır. Dolayısıyla bu değerin sıfıra ne kadar yakın olması durumunda tahmin edilen değerin de o kadar doğruya yakınsadığı söylenebilir. Oluşturulan modellerin tümünde eğitim ve test verileri ayrıştırılırken 10-katlı çapraz doğrulama yöntemi seçilmiştir. Bu yöntemde veriler öncelikle 10 ayrı gruba ayrılır ve bir grup test amaçlı kullanılırken geriye kalan diğer dokuz grup da eğitim amaçlı kullanılır. Tüm veriler hem test hem de eğitim amaçlı kullanılması için bu işlem 10 kez tekrarlanır ve gruplar değiştirilir. Veri madenciliği yöntemlerinden Weka programı içerisinde yer alan aşağıdakiler kullanılmış ve tahmin başarıları birbirleriyle karşılaştırılmıştır.

- Functions
- GaussianProcess
- LinearRegression
○ SMOreg

- lazy 
○ IBk

○ KStar

○ LWL

- Meta

○ Bagging_DecisionStump

○ Bagging_M5P

○ Bagging_MultiLayerPerception

○ Bagging_RepTree

- $\quad$ Misc

○ InputMappedClassifier

- rules
- DecisionTable
○ M5Rules
- ZeroR

- Trees
○ DecisionStump
○ M5P
- RandomForest
- RandomTree
○ REPTree

\section{Bulgular}

Yabancı Dil-II dersini alan öğrencilerin ders geçme notları birden faza yöntem ile tahmin edilmiş ve ortalama mutlak hata değerleri, ortalama karesel hatanın karekökü ile korelasyon katsayısı değerleri karşılaştırılmıştır. Aşağıdaki tabloda her bir öğrenme yöntemi ve sonuçları gösterilmiştir.

Tablo 2. Öğrenme Yöntemi ve Sonuçları

\begin{tabular}{|c|c|c|c|c|}
\hline Yöntem Grup Adı & Yöntem Adı & $\begin{array}{l}\text { Ortalama } \\
\text { Mutlak Hata }\end{array}$ & $\begin{array}{l}\text { Ortalama Karesel } \\
\text { Hata Karekökü }\end{array}$ & $\begin{array}{l}\text { Korelasyon } \\
\text { Katsayısı }\end{array}$ \\
\hline \multirow[t]{3}{*}{ Functions } & GaussianProcess & 1.3408 & 1.7463 & 0.7898 \\
\hline & LinearRegression & 1.3453 & 1.7506 & 0.7887 \\
\hline & SMOreg & 1.3213 & 1.7666 & 0.7588 \\
\hline \multirow[t]{3}{*}{ lazy } & IBk & 1.5756 & 2.3967 & 0.6353 \\
\hline & KStar & 1.4889 & 2.0153 & 0.7102 \\
\hline & LWL & 1.6355 & 2.1971 & 0.6360 \\
\hline \multirow[t]{4}{*}{ Meta } & Bagging (DecisionStump) & 1.6990 & 2.2244 & 0.6251 \\
\hline & Bagging (M5P) & 1.2192 & 1.6688 & 0.8102 \\
\hline & $\begin{array}{c}\text { Bagging } \\
\text { (MultiLayerPerception) }\end{array}$ & 1.7011 & 2.0989 & 0.6835 \\
\hline & Bagging (RepTree) & 1.3357 & 1.8222 & 0.7686 \\
\hline Misc & InputMappedClassifier & 2.3480 & 2.8485 & -0.0729 \\
\hline \multirow[t]{3}{*}{ rules } & Decision Table & 1.2891 & 1.7578 & 0.7869 \\
\hline & M5Rules & 1.2636 & 1.7195 & 0.7972 \\
\hline & ZeroR & 2.3480 & 2.8485 & -0.0729 \\
\hline \multirow[t]{5}{*}{ Trees } & DecisionStump & 1.7037 & 2.2597 & 0.6082 \\
\hline & M5P & 1.2575 & 1.7146 & 0.7985 \\
\hline & RandomForest & 1.3813 & 1.8581 & 0.7578 \\
\hline & RandomTree & 1.6071 & 2.4369 & 0.6335 \\
\hline & REPTree & 1.4325 & 1.9841 & 0.7242 \\
\hline
\end{tabular}


Yukarıdaki Tablo 2 dikkatle incelendiğinde en düşük ortalama mutlak hata değerine sahip modelin Bagging (M5P) yöntemi ile oluşturulduğu görülecektir. DecisionTable, M5P ve M5Rules yöntemleri de bu modele yakın hata değerleri elde etmiş̧tir. Fakat InputMappedClassifier ve ZeroR yöntemleri en yüksek ortalama mutlak hata değerine sahiptir. Ayrıca bu yöntemlerin korelasyon katsayılarına dikkat edilirse negatif bir değerdir.

En iyi tahmin modeli olan Bagging (M5P) için elde edilen tahmin değerleri ve gerçek değerlerin durumunu göstermek için 10 katlı çapraz doğrulamadan birincisi içerisinden ilk 50 adet örnek alınmış ve aşağıdaki grafikte gösterilmiştir.

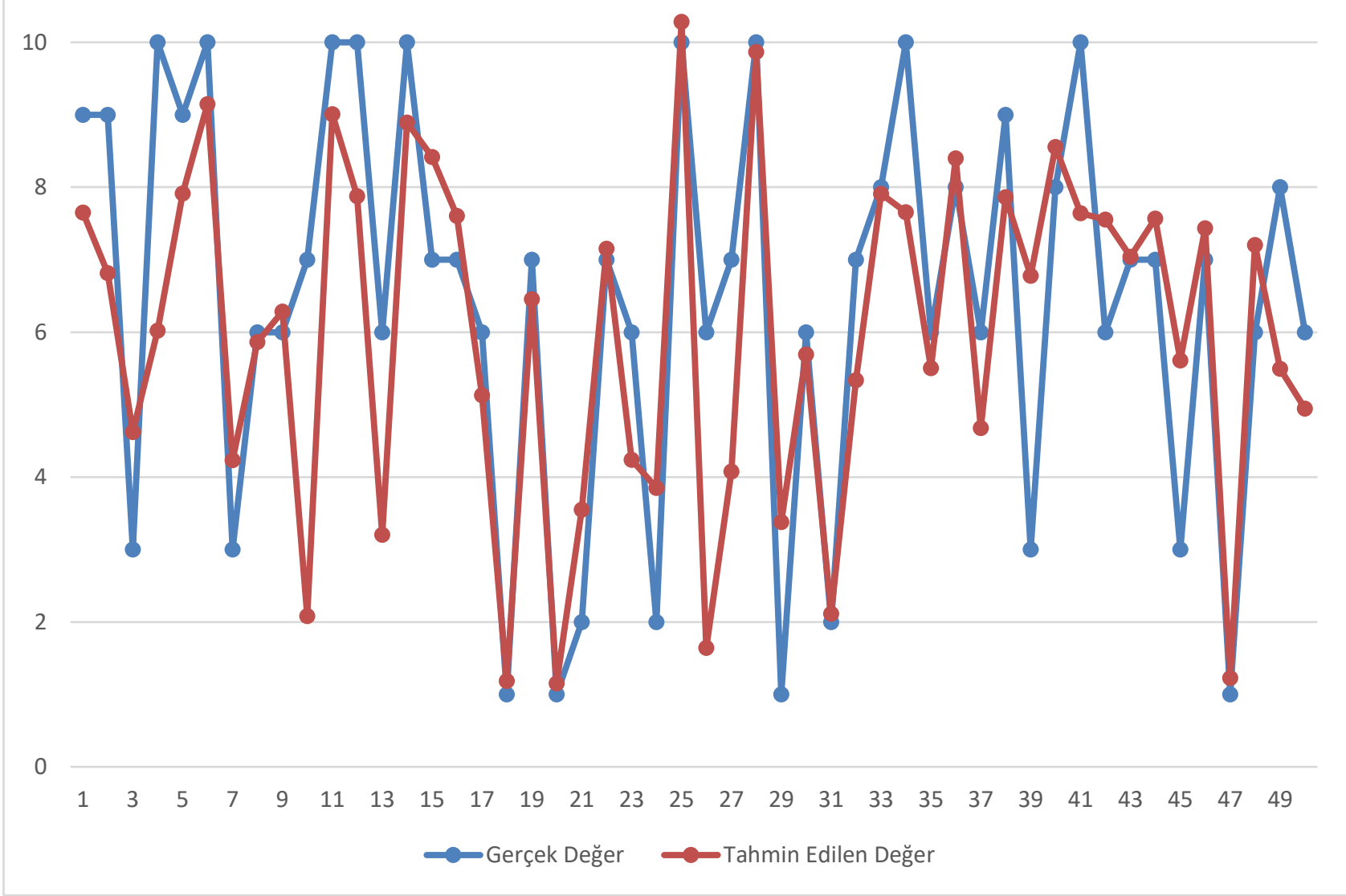

Şekil 1. Gerçek Değer ve Tahmin Edilen Değerin Durumu

Yukarıdaki şekil dikkatle incelenirse büyük bir oranda tahmin edilen değerlerin gerçek değerlere yakınsadığı görülecektir. 1-10 arasındaki gerçek değerler için ortalama 1.21 sapma değeri tahminler elde edilmesi modelin başarılı olduğunu göstermektedir.

\section{Tartışma ve Sonuç}

Çalışma kapsamında 2017-2018 Eğitim-Öğretim yılındaki Yabancı Dil-II dersini alan öğrencilerin ders geçme notu veri madenciliği yöntemleri kullanılarak tahmin edilmiş̧ir. Böylece öğrencinin başarı durumunu önceden öngörerek önlem almasına yardımcı olabileceği düşünülmektedir. Veri madenciliği uygulamalarında yaygın olarak kullanılan Weka programı aracılı̆̆ıyla veriler 19 farklı yöntem ile analiz edilmiş ve tahmin başarı oranları karşılaştırılmıştır. Bir ile 10 arasındaki notları yaklaşık 1.21 sapma değeri ile tahminler yapılmıştır. Bu da yaklaşık \%12 oranında bir sapmaya karşılık gelmektedir. Buradaki uygulamada en iyi tahmin başarısı Bagging (M5P) ile elde edilmiştir. Alan (2012) ise benzer bir çalışmasında başarı notunun sınıflandırılmasını öngörmek için SimpleCART algoritması ile en iyi sonuçları elde etmiştir. Sınıflandırma yöntemleri ile farklı tahmin çalışmaları da vardır (Aydoğan ve Zırhlıoğlu, 2018; Akçapınar, Altun ve Aşkar, 2015). Aydemir (2017) de not ortalamasına göre yaptığı tahminlerde SMO algoritması ile mezuniyet yılına göre yaptı̆̆ tahminlerde ise J4.8 ve NaiveBayes algoritmaları ile en iyi sonuçları elde etmiştir. Can, Özdil ve Yılmaz (2018) ise öğrencilere uygulanan bir ölçek ile ders başarısını etkileyen unsurları lojistik regresyon yöntemi ile tahmin etmiş ve ders tekrarı sayısı ile yenilikçi uygulamaların etkilediğini belirlemiştir. Kılınç (2015) sınıflandırma algoritmalarından J4.8 ve kNN ile birliktelik algoritmalarından Apriori ve Predictive Apriori kullanarak atılma politikasındaki değişiklik ile öğrencilerin not durumları arasındaki ilişkiyi bulmuştur. Çalışması sonunda eğitim sürelerinin, burs ya da kredi alma durumuna göre değiştiğini ve ayrıca maddi durumları ile annelerinin çalışması arasında bağlantı olduğunu görmüştür. Demir (2015) de öğrencilerin sınavlara yönelik not durumlarını yapay sinir ağları ile tahmin etmeye çalışmış ve 0.63 korelasyon katsayısı elde etmiştir. Fakat buradaki çalı̧̧mada ise 0.81 korelasyon katsayısı elde ederek daha iyi tahminler elde edilmiştir. Şengür ve Tekin (2013) ise öğrencilerin mezuniyet notlarını tahmin etmek için yaptıkları çalışmada karar ağaçlarını kullanarak 0.76 korelasyon katsayısı ile tahminler elde ederken, yapay sinir ağları kullanarak korelasyon 0.93 değeri ile tahminler elde etmişlerdir. Bu çalışmada yalnızca birinci ve ikinci sınıf yılsonu not ortalamaları kullanılmıştır. Çalışma yapısı itibariyle buradaki çalışmadan farklılık göstermesi nedeniyle sonuçların farklı olduğu düşünülmektedir. Çalışma içerisinde 
kullanılmayan ve ders başarısına etki eden başka unsurların belirlenmesi ve tekrardan hem buradaki yöntemler ile hem de başka yöntemler ile analizlerin yapılması alana katkı sunması açısından yararlı olacaktır. Ayrıca buradaki çalışmanın sonuçları ile karşılaştırılması da pozitif ve negatif durumların ortaya çıkarılması açısından önerilmektedir. 


\section{Kaynakça}

Akçapınar, G., Altun, A. \& Aşkar, P. (2015). Modeling Students' Academic Performance Based on Their Interactions in an Online Learning Environment, Illköğretim Online, 14(3), 815-824.

Akpınar, H. (2000). Veri tabanlarında bilgi keşfi ve veri madenciliği, İ.Ü. İşletme Fakültesi Dergisi, 29 (1), 1-22.

Alan, M. A. (2012). Veri Madenciliği ve Lisansüstü Öğrenci Verileri Üzerine Bir Uygulama. Dumlupinar Üniversitesi Sosyal Bilimler Dergisi, 33(1), 165-174.

Altıışık, U. (2006). Öğrenci bilgi sisteminde veri madenciliğinin uygulanması, Kocaeli Üniversitesi, Yüksek Lisans Tezi, Fen Bilimleri Enstitüsü.

Aydemir, B. (2017). Veri Madenciliği Yöntemleri Kullanarak Meslek Yüksekokulu Öğrencilerinin Akademik Başarı Tahmini, Yüksek Lisans Tezi, Pamukkale Üniversitesi, Fen Bilimleri Enstitüsü.

Aydemir, E. (2018). Weka ile Yapay Zekâ, Seçkin Yayınevi, Ankara.

Aydoğan, İ. \& Zırhlığlu, G. (2018). Öğrenci Başarılarının Yapay Sinir Ağları ile Kestirilmesi, Yüzüncü Yıl Üniversitesi Eğitim Fakültesi Dergisi, 15(1), 577-610.

Baykal, A. (2006). Veri Madenciliği Uygulama Alanları, DÜ Ziya Gökalp Eğitim Fakültesi Dergisi, 7 (1), 95-107.

Beitel, S. E. (2005). Applying Artificial Intelligence Data Mining Tools to the Challenges of Program Evaluation, Ph. D. The Sis, University of Connecticut, Connecticut.

Can, Ş., Özdil, T. \& Yılmaz, C. (2018). Üniversite Öğrencilerinin Ders Başarısını Etkileyen Faktörlerin Lojistik Regresyon Analizi İle Tahminlenmesi. International Review of Economics and Management, 6 (1), 28-49.

Demir, M. (2015). Predicting Pre-Service Classroom Teachers' Civil Servant Recruitment Examination's Educational Sciences Test Scores Using Artificial Neural Networks. Educational Sciences: Theory and Practice, 15(5), 1169-1177.

Doğan, A. (2002). Yapay Zekâ. İstanbul: Kariyer Yayınc1lık.

Erdoğan, Ş. Z. (2004). Veri Madenciliği ve Veri Madenciliğinde Kullanılan K-Means Algortimasının Öğrenci Veri Tabanında Uygulanması, İstanbul Üniversitesi, Yüksek Lisans Tezi, Fen Bilimleri Enstitüsü.

Han, J. \& Kamber, M. (2006). Data Mining: Concepts and techniques (Second edition), San Francisco: Morgan Kaufman

İnan, O. (2003). Öğrenci İşleri Veri Tabanı Üzerinde Veri Madenciliği Uygulamaları, Konya Selçuk Üniversitesi, Yüksek Lisans Tezi, Fen Bilimleri Enstitüsü.

Karip, E. (2012). Ölçme ve Değerlendirme. Ankara: Pegem Akademi Yayınc1lık.

Kılınç, Ç. (2015). Üniversite Öğrenci Başarısı Üzerine Etki Eden Faktörlerin Veri Madenciliği Yöntemleri İle İncelenmesi, Yüksek Lisans Tezi, Eskişehir Osmangazi Üniversitesi, Fen Bilimleri Enstitüsü.

Luan, J. (2002). Data Mining and Knowledge Management in Higher Education-Potential Applications. 42nd Associate of Institutional Research International Conference, Toronto, Canada.

Oğuzlar, A. (2004). Veri Madenciliğinde Birliktelik Kuralları, Öneri, 6 (22), 315-321.

Sembiring, S., Zarlis, M., Hartama, D., Ramliana, S. \& Wani, E. (2011). Prediction of student academic performance by an application of data mining techniques. In International Conference on Management and Artificial Intelligence IPEDR, 6 (1), 110-114.

Shovon, M. H. I. \& Haque, M. (2012). Prediction of student academic performance by an application of k-means clustering algorithm. International Journal of Advanced Research in Computer Science and Software Engineering, 2(7), 353-355.

Siemens, G. \& D Baker, R.S.J. (2012). Learning Analytics and Educational Data Mining: Towards Communication and Collaboration. 2nd international conference on learning analytics and knowledge, Vancouver, Canada.

Şengür, D. \& Tekin, A. (2013). Öğrencilerin mezuniyet notlarının veri madenciliği metotları ile tahmini. Bilişsim Teknolojileri Dergisi, 6(3), 7-16.

Turgut, M.F. \& Baykul, Y. (2013). Eğitimde Ölçme ve Değerlendirme. Ankara: Pegem Akademi.

Yurtoğlu, H. (2005). Yapay Sinir Ağları Modellemesi ile Öngörü Modellemesi: Bazı Makroekonomik Değişkenler için Türkiye Örneği, Uzmanlık Tezi, DPT, Ankara. 